\title{
THE COMFORT PROPERTIES OF TWO DIFFERENTIAL-SHRINKAGE POLYESTER WARP KNITTED FABRICS
}

\author{
Qing Chen, Xuhong Miao, Haiwen Mao, Pibo Ma, Gaoming Jiang
}

The School of Textile and Clothing, Jiangnan University, Wuxi 214122, PRC

e-mail: 12071107@qq.com

\begin{abstract}
:
Single-layered warp knitted fabrics were produced by the 60D/36F (containing 36 filaments) polyester yarn with differential shrinkage (DS) property in this study. Due to the differential shrinkage property, the fabric becomes curly and bulkier, simulating cotton fabric in terms of its appearance and fabric handle. The performance and appearance of these DS polyester warp knitted fabrics were evaluated objectively and subjectively. The testing results demonstrated that the DS polyester warp knitted fabric had better abrasion property, worse pilling resistance due to the mechanical property of polyester yarn when compared with $100 \%$ cotton warp knitted fabric. Meanwhile, lower water vapour permeability and air resistance were found for DS polyester warp knitted fabric resulting from the dense structure of yarn shrinkage after heat-moisture treatment. Besides, the fabric handle was evaluated by Kawabata evaluation system and subject to trial under dry and wet fabric condition. DS polyester warp knitted fabrics provide better recovery under low stress mechanical pressure. The subjective evaluation result shows that the warp knitted fabrics made of DS polyester had similar handle against cotton warp knitted fabric in terms of prickle, smooth, comfort and dry feeling in both dry and wet testing conditions.
\end{abstract}

\section{Keywords:}

Warp knit; Polyester; Comfort; Subjective evaluation; Handle

\section{Introduction}

Cotton is comfortable to wear in mild weathering condition; it, however, is a hygroscopic material which is not easy-dry and gives a clingy sensation when wetted. On the other hand, the conventional continuous filament yarns, like polyester and nylon, are nonhygroscopic which tend to dry faster and give a drier feel. Synthetic yarn or blended yarn was therefore used to improve the comfort property of the fabric. For example, cottonacrylic yarn [1] and cotton-polyester yarn [2] were studied for its air permeability and wicking property. Additionally, the effect of blend ratio was also studied to improve the mechanical property of cotton-polyester yarn [3], comfort property of wool-cashmere yarn [4] and moisture management property of cotton-bamboo yarn [5]. In addition, optimum drafting conditions of noncircular polyester and cotton blended yarns were examined in Su et al.'s study [6]. Indeed, textile products made by the mixture of profiled polyester fibres and nature cotton fibres can not only provide a better sense of touch but also comfort in respect of moisture absorption and release property [7]. Thermal comfort properties of Viloft/cotton and Viloft/polyester weft knitted fabrics were also studied [8]. The moisture management properties of various blended fabrics were studied, including cotton/polyester/ rayon blend simple rib, cotton, cotton/viscose blend, polyamide $1 \times 1$ interlock and polyester double rib [9], bamboo plain jersey knitted fabric [10], micro-denier polyester filament, spun polyester, polyester/cotton moisture finished fabric [11], and single jersey of wool/ polyester and wool/bamboo for the base of layer of active sportswear [12]. By over viewing above research, the single layered warp knitted fabrics were seldom studied.
Fully drawn multifilament polyester yarns, with different linear densities, are produced by a single-head mechanical crimp texturing machine [13]. A high bulk polyester filament yarn was developed by fully drawn PET and POY [14]. Maximum yarn bulk, shrinkage and minimum yarn strength of acrylic fibres are obtained at about $40 \%$ shrinkable fibre blending ratio [15].

The hand of textiles is a crucial factor affecting the merchandise behaviour [16]. Subjective and/or objective evaluations are employed to assess the handle of fabrics or garments [16]. Kawabata Evaluation System and Fabric Assurance by Simple Testing and PhabrOmeter Fabric Evaluation System are widely used to conduct the objective evaluation. By using them, the effect of different material [17], fibre/yarn property like crosssectional shape and fineness [18,19], yarn property [20,21,22], fabric producing process [23] and finishing treatment [24,25] were analysed. Besides, the subjective evaluation is also applied to assess the fabric/garment handle to reflect the real touch of wearing [26].

In fact, texturing can impart bulkiness to continuous filament yarns. False-twist (FT) stretch and set yarns as well as bulked continuous filament yarns are examples for textured yarns. However, the texturing yarn is not suitable for fine gauge warp knitting and high speed production. To overcome these limitations, two types of PET continuous filament yarn were blended to obtain a bulk yarn after heat and moisture treatment. A yarn was produced by blending two types of PET continuous filament yarns with differential shrinkage property and followed by heat and moisture treatment process. This paper aims to 
compare this blended warp knitted fabrics against the cotton warp knitted fabrics in terms of physical, comfort properties. Fabric handle of all DS and cotton warp knitted fabrics was assessed objectively by Kawabata Evaluation System as well. Moreover, subjective handle evaluation was conducted to assess the $100 \%$ cotton and $100 \%$ polyester woven, weft knitted and warp knitted fabrics in both fabric dry and wet condition. Six perception components were selected in terms of cool-warm, prickle-unprickle, roughness-smoothness, discomfort-comfort, polyester-like - cotton like in dry condition, as well as clammy- dry in wet condition.

\section{Experimental}

\subsection{Sample}

The 60D/36F (containing 36 filaments) blended (filament yarn was constructed by two materials, giving a differential shrinkage property). This differential-shrinkage polyester is made by two components - Fully Drawn Yarn (FDY) and Partially Oriented Yarn (POY). FDY is heat treated after the drawing process contributing to a lower degree of shrinkage while POY is an untreated filament which is likely to shrink much after heat treatment process. Due to the differential shrinkage property, the FDY part will become fluffy after the heat treatment process which simulates cotton fibre. After the heat and moisture treatment, the blended yarn shrinks to about $23 \%$. The breakage elongation of yarn is $15.75 \%$ and breakage strength of yarn is $4.95 \mathrm{cN} / \mathrm{dtex}$. The polyester fabrics were produced and treated under conventional dyeing and finishing process of polyester material.

The SEM images of polyester warp knitted fabric with differential-shrinkage property and $100 \%$ cotton warp knitted fabric are demonstrated in Figure 1. The mixture of high and low shrinkage component creates bulk appearance as shown in Figure 1 (a). During the relaxation process, the high-shrinkage component (i.e. POY) moves towards the centre of the yarn and bends the low-shrinkage component (i.e. FDY), leading to bulk development. For the cotton warp knitted fabric, it is made of $120 / 2$ Ne cotton.
E28 tricot warp knitting machine was used to produce the fabrics. Two bars were used for knitting polyester fabrics in tricot stitch, locknit stitch and satin stitch. In order to study the effect of density, four densities were obtained for the locknit structure. The weight of polyester fabric ranges from 162$194.3 \mathrm{~g} / \mathrm{m}^{2}$ while the thickness ranges from $0.529-0.613 \mathrm{~mm}$. The $100 \%$ cotton fabric in tricot stitch was also knitted and its performance was compared against the differential-shrinkage polyester fabrics. The weight and thickness of cotton warp knitted fabric are $153.5 \mathrm{~g} / \mathrm{m}^{2}$ and $0.549 \mathrm{~mm}$.

\section{$\underline{2.2}$ Test methods}

Various objective parameters were measured including vertical wicking rate, air resistance, water vapour permeability, antistatic electricity, abrasion, pilling resistance and fabric handle. Besides, subjective evaluations of fabric handle were also assessed, including Cool-Warm, Prickle-Unprickle, RoughSmooth, Discomfort-Comfort and Polyester-like - Cotton-like in both dry and wet condition as well as Clammy-Dry feeling in wet condition.

\section{Vertical wicking}

In the vertical wicking test, a fabric strip with $25 \mathrm{~mm}$ wide and $250 \mathrm{~mm}$ long was hung vertically from a clamp with the lower $25 \mathrm{~mm}$ of the sample immersed into the water according to AATCC standard RA63 [27]. After 30 min of water spreading, the length of water spread was recorded. Specimens were tested in both lengthwise and width-wise directions.

\section{Pilling resistance}

The pilling resistance of the fabric was tested according to ASTM D4970[28]. The test was performed on Martindale abrasion tester and the test sample was set to run for 1000 circles.

\section{Abrasion resistance}

The abrasion resistance of the fabric was tested according to ASTM D3884 [29]. The test sample was put on the rotary platform double head abrader. The number of circle was set at

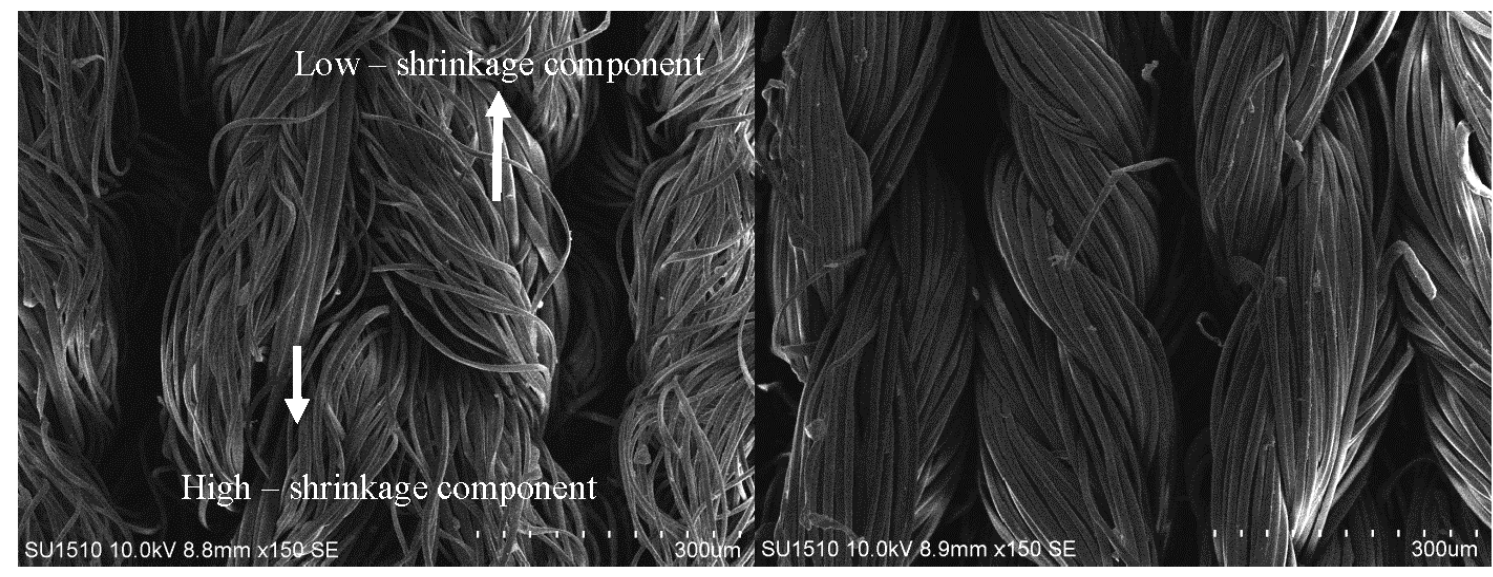

(a) DS polyester warp knitted fabric

(b)Cotton warp knitted fabric

Figure 1. SEM images of warp knitted fabrics made of (a) differential-shrinkage polyester yarn and (b) cotton yarn 
Table 1. Specifications of warp knitted fabrics made of differential-shrinkage (DS) polyester or cotton yarn

\begin{tabular}{|c|c|c|c|c|c|c|c|c|}
\hline \multirow{2}{*}{ Sample } & \multirow{2}{*}{ Material } & \multirow{2}{*}{$\begin{array}{l}\text { Knitting } \\
\text { notation }\end{array}$} & \multirow{2}{*}{ Structure } & \multirow{2}{*}{$\begin{array}{l}\text { Warp density } \\
\text { On machine } \\
\text { (loop/cm) }\end{array}$} & \multirow{2}{*}{$\begin{array}{l}\text { Weight } \\
\left(\mathrm{g} / \mathrm{m}^{2}\right)\end{array}$} & \multirow{2}{*}{$\begin{array}{l}\text { Thickness } \\
\text { (mm) }\end{array}$} & \multicolumn{2}{|c|}{$\begin{array}{l}\text { Density } \\
\text { (loop/cm) }\end{array}$} \\
\hline & & & & & & & Weft & Warp \\
\hline A & \multirow{6}{*}{$\begin{array}{c}100 \% \\
\text { differential- } \\
\text { shrinkage } \\
(\mathrm{DS}) \\
\text { polyester } \\
(60 \mathrm{D} / 36 \mathrm{~F})\end{array}$} & $\begin{array}{l}\text { GB1:1-0/1-2// } \\
\text { GB2:1-2/1-0// }\end{array}$ & Tricot & 16.4 & 179.6 & 0.529 & 17.2 & 30 \\
\hline B-1 & & \multirow{4}{*}{$\begin{array}{l}\text { GB1:1-0/2-3// } \\
\text { GB2:1-2/1-0// }\end{array}$} & \multirow{4}{*}{ Locknit } & 14.3 & 162 & 0.581 & 16.5 & 23.6 \\
\hline B-2 & & & & 16.4 & 164.7 & 0.579 & 17.2 & 26.4 \\
\hline B-3 & & & & 18.1 & 171.5 & 0.573 & 17.5 & 27.5 \\
\hline B-4 & & & & 20 & 183.7 & 0.568 & 17.5 & 28.3 \\
\hline C & & $\begin{array}{l}\text { GB1:1-0/3-4// } \\
\text { GB2:1-2/1-0// }\end{array}$ & Satin & 16.4 & 194.3 & 0.613 & 18.5 & 24 \\
\hline D & $\begin{array}{c}100 \% \text { cotton } \\
(120 / 2 \mathrm{Ne})\end{array}$ & $\begin{array}{l}\text { GB1:1-0/1-2// } \\
\text { GB2:1-2/1-0// }\end{array}$ & Tricot & 24 & 153.5 & 0.549 & 14 & 26 \\
\hline
\end{tabular}

2000 , and the pressure loading is $250 \mathrm{~g}$. The fabric weight loss was calculated by equation (1):

The weight loss $=\left(\mathrm{W}_{\text {before }}-\mathrm{W}_{\text {after }}\right) / \mathrm{W}_{\text {before }}{ }^{*} 100 \%$

\section{Air permeability}

According to GB/T5453 [30], the air permeability was measured under the $100 \mathrm{~Pa}$ pressure difference. The air permeability is expressed in $\mathrm{mm} / \mathrm{s}$.

\section{Water vapour permeability}

According to GB/T12704 [31], the test condition of instrument is $38 \pm 0.5^{\circ} \mathrm{C}, 90 \pm 2 \%$, the sample radius is $35 \mathrm{~mm}$. The water vapour permeability is calculated by equation (2):

WVT $=24 \times \Delta \mathrm{m} / \mathrm{s} \times \mathrm{t} \quad\left(\mathrm{g} / \mathrm{m}^{2} \cdot \mathrm{day}\right)$

where WVT is water vapour permeability, $m$ is the weight difference, $s$ is testing area and time is testing time.

\section{Kawataba evaluation system}

Kawabata evaluation system (KES-F) was used to evaluate the handle of the fabric. It contains shearing, tensile, compression, bending properties (KES-F1, F2, F4-AP1, Kato Tech. Co.).

\section{Subjective test of handle}

Twenty female college students are invited for the subjective test. They were asked to sign the consent form before the start of the test. Eyeshade should be worn to avoid any visual interference including colour, pattern or texture of the sample. The sample size is $30 \times 20 \mathrm{~cm}$. The specifications of the samples are listed in Table 2. Among the eleven fabrics, three of them are woven fabrics, four are weft knitted fabrics and the rest is warp knitted fabrics. Four warp knitting fabrics are selected from this experiment. Sample Nos. 8,9,10 and 11 are corresponding to samples A, B-1, C and D. On the other hand, three are made of cotton while the rest is made of polyester or DS polyester.

Before the test, the fabric samples were conditioned in the testing condition $\left(25{ }^{\circ} \mathrm{C}\right.$ and $65 \%$ R.H.) for 24 hours. The subjects were asked to acclimatize in the climatic chamber for 15 min. During the test, the sample was placed on subject's forearm with inner surface of the fabric contacted with the skin. The sample was shifted across subject's forearm in left/right direction at the same speed until the rating of contact feeling was given. Six questions were asked when manipulating with the fabric. They are cool(0)-warm(100), prickle(0)-unprickle(100), rough(0)-smooth(100), discomfort(0)-comfort(100), polyesterlike (0)-cotton-like (100) in both dry and wet condition, clammy(0)-dry(100) in fabric wet condition. The wet condition of the fabric can be obtained by dropping $5 \mathrm{ml}$ of water onto the fabric. Once the water droplet was absorbed by the fabric completely, the wetted sample was ready to be put on forearm.

\section{Results and discussion}

\section{Vertical wicking}

Due to the use of hydrophilic softener in the treatment process, the vertical wicking height is significantly higher for the DS polyester fabrics than for the cotton fabrics after $30 \mathrm{~min}$ of water spreading as summarized in Table 3. On the other hand, the effect of knit structure is not as significant as the effect of material. Regarding the effect of fabric density/tightness, liquid transport property decreases with the increase of fabric density/tightness in general $[10,32]$. But in this study, it is not evident that vertical wicking height is related to fabric density. This might attribute to the small difference in density among samples B-1, B-2, B-3 and B-4. 
Table 2. Fabric specifications

\begin{tabular}{|c|c|c|c|c|c|}
\hline $\begin{array}{c}\text { Sample } \\
\text { code }\end{array}$ & Fabric type & Material & Structure & $\begin{array}{c}\text { Weight } \\
\left(\mathbf{g} / \mathbf{m}^{2}\right)\end{array}$ & $\begin{array}{c}\text { Thickness } \\
(\mathbf{m m})\end{array}$ \\
\hline 1 & Woven & $100 \%$ normal FDY polyester & Plain & 103 & 0.203 \\
\hline 2 & Woven & $100 \%$ normal FDY polyester & Plain & 110 & 0.326 \\
\hline 3 & Woven & $100 \%$ cotton & Plain & 150 & 0.477 \\
\hline 4 & Weft knitted & $100 \%$ differential-shrinkage (DS) polyester & Rib & 167 & 0.521 \\
\hline 5 & Weft knitted & $100 \%$ differential-shrinkage (DS) polyester & Interlock & 201 & 0.751 \\
\hline 6 & Weft knitted & $100 \%$ differential-shrinkage (DS) polyester & Plain & 129 & 0.357 \\
\hline 7 & Weft knitted & $100 \%$ cotton & Plain & 110 & 0.457 \\
\hline 8 & Warp knitted & $100 \%$ differential-shrinkage (DS) polyester & Tricot & 179 & 0.529 \\
\hline 9 & Warp knitted & $100 \%$ differential-shrinkage (DS) polyester & Locknit & 162 & 0.581 \\
\hline 10 & Warp knitted & $100 \%$ differential-shrinkage (DS) polyester & Satin & 194 & 0.613 \\
\hline 11 & Warp knitted & & Tricot & 153 & 0.549 \\
\hline
\end{tabular}

\section{Pilling resistance}

The pilling resistance of fabric is denoted by the grading as shown in Table 3 with higher grading representing better pilling resistance. For most of the DS polyester warp knitted fabrics, their grading is approximate to 4 which is lower than that of cotton fabric, implying relatively poorer pilling resistance. For higher grade cotton fabric, the entangled fibre will not cling to the surface of fabric, instead the pills will easily be detached from the fabric, contributing to clearer surface. In the case of higherstrength fibre, like polyester, the pills will tend to remain in place. This could explain high grading observed on those DS polyester fabrics. The pilling resistance also increases with stitch density [33]. For sample B-4, its pilling resistance is higher than those fabrics with lower stitch density (i.e. samples B-1, B-2 and B-3).

\section{Abrasion resistance}

The abrasion resistance property of fabric is shown in Table 3. It can be seen that the weight loss of DS polyester fabrics is lower than the cotton fabric after 2000 cycles of abrasion, implying better abrasion resistance. Researchers also suggest that polyester filaments are considered to have good abrasion resistance [34]. Among all DS polyester fabrics, the weight reduction is the lowest for sample $C$, followed by sample $B$ whilst sample A got higher reduction in fabric weight. This finding might relate to fabric thickness where sample $A$ had the lowest thickness $(0.529 \mathrm{~mm})$ whereas sample $C$ had the highest thickness $(0.613 \mathrm{~mm})$. For fabrics with higher thickness, they are able to resist heavier abrasion. On the other hand, the cotton sample had the highest weight loss since the strength of cotton fibre is comparatively lower.

\section{Air permeability}

The air permeability of the fabrics is shown in Table 3. From samples B-1 to B-4, the air permeability of the fabric tends to decrease with the increase of stitch density. With higher stitch density, the fabric becomes tightly packed which minimises the pores within the fabric and contributes to poorer air permeability. In addition, the cotton fabric has higher air permeability. This is because the cotton fabric has the lowest stitch density, fabric weight and thickness. Moreover, the observation also demonstrates that the warp knitted DS polyester fabric made of two differential shrinkage yarns has lower air permeability value. It is probably due to high shrinkage of material and higher tightness of the fabric.

\section{Water vapour permeability}

The water vapour permeability of fabrics is shown in Table 3. It can be observed that cotton fabric (i.e. sample D) has the highest water vapour permeability. This might be attributed to the lower stitch density, lower weight as well as lower tightness of the cotton fabric. Among the six DS polyester fabrics, sample A had highest water vapour permeability due to its short underlaps and lower thickness. In addition, it can be observed that the water vapour permeability of the fabric decreases with the increase of fabric density even though fabric thickness decreases slightly. Researcher suggests that water vapour permeability of fabric is affected not only by fabric thickness, but also fabric porosity/tightness [9].

\section{Kawabata evaluation test}

\section{Tensile}

Higher tensile energy (WT) means it is easier to extend under the same extension force. Cotton fabric (i.e. sample $D$ ) has higher WT value $\left(\mathrm{WT}_{\text {warp }}=51.8 ; \mathrm{WT}_{\text {weft }}=49.4\right)$ than the DS polyester fabrics (from 16.5 to 39.95 ). Comparing the cotton fabric (i.e. sample D) with the corresponding DS polyester sample with the same structure (i.e. sample A), the cotton fabric is easier to extend under same extension force. Among DS polyester fabrics, sample A has the highest WT value due to its short underlaps while sample $C$ has the lowest WT value due to its long underlaps. The long underlap will hinder the extension of fabric. 
Table 3. Objective measurement result

\begin{tabular}{|c|c|c|c|c|c|c|}
\hline \multirow{2}{*}{ Sample } & \multicolumn{2}{|c|}{ Vertical wicking height $(\mathrm{cm})$} & \multirow{2}{*}{$\begin{array}{l}\text { Pilling } \\
\text { resistance } \\
\text { (grade) }\end{array}$} & \multirow{2}{*}{$\begin{array}{c}\text { Abrasion } \\
\text { (Reduction of } \\
\text { fabric weight } \\
\text { in } \% \text { ) }\end{array}$} & \multirow{2}{*}{$\begin{array}{c}\text { Air } \\
\text { permeability } \\
(\mathrm{mm} / \mathrm{s})\end{array}$} & \multirow{2}{*}{$\begin{array}{c}\text { Water vapour } \\
\text { permeability } \\
\left(g / m^{2} \cdot \text { day }\right)\end{array}$} \\
\hline & warp & weft & & & & \\
\hline A & 16.4 & 16.2 & 4 & 0.9 & 151.72 & 6202 \\
\hline B-1 & 17.7 & 17.2 & 4 & 0.67 & 230.52 & 6143 \\
\hline B-2 & 18.9 & 18.2 & 4 & 0.11 & 182.56 & 6296 \\
\hline B-3 & 17.9 & 17.2 & 4 & 0.2 & 175.1 & 5894 \\
\hline B-4 & 19.2 & 18.6 & 5 & 0.35 & 141.09 & 5534 \\
\hline C & 18.4 & 18.2 & 4 & 0.06 & 184.48 & 6084 \\
\hline $\mathrm{D}$ & 10.4 & 10.1 & 5 & 1.2 & 1095.7 & 6330 \\
\hline
\end{tabular}

Tensile resilience (RT) indicates the ability of fabric to withstand external stress during extension. The cotton fabric (i.e. sample D) has lower RT $\left(R T_{\text {warp }}=24.81 ; R T_{\text {weft }}=29.25\right)$ than the DS polyester fabrics (from 40.49 to 57.02 ). It means that it is easier for the DS polyester fabrics to recover to its original shape after the removal of tensile stress.

It should be noticed that $W T_{\text {warp }}$ is smaller than $\mathrm{WT}_{\text {weft }}$ for most samples, implying that the weft direction is easier to be extended than the warp direction. On the other hand, $\mathrm{RT}_{\text {warp }}$ is larger than $\mathrm{RT}_{\text {weft }}$, suggesting that the warp direction has better ability to withstand external stress. This is because the warp density is almost twice the number of weft density.

\section{Shearing}

Shearing is an important determinant of the handle and drape of fabrics. The shear rigidity $(G)$ reflects the subjective handle of the fabric. Larger shearing rigidity gives stiffer handle. Comparing the tricot DS polyester fabric (i.e. sample A) with the tricot cotton fabric (i.e. sample D), DS polyester fabric has stiffer handle than cotton fabric.

Shear stress $(2 \mathrm{HG})$ reflects the ability to recover after shearing at $0.5^{\circ}$ shear angle. The greater value of the shear stress, the worse will be the recovery ability of the fabric. Cotton fabric and DS polyester fabric have similar shear stress value, suggesting similar recovery ability after shearing deformation.

$G_{\text {warp }}$ is larger than $G_{\text {weft }}$, implying that the weft direction is easier to extend than the warp direction. $2 \mathrm{HG}_{\text {warp }}$ is smaller than $2 \mathrm{HG}_{\text {weft, }}$ indicating that the warp direction had better ability to withstand external stress. This is because the warp density almost double the number of the weft density.

\section{Bending}

The bending property is a critical determinant of fabric handle as well. Lower bending rigidity $(B)$ and lower bending moment $(2 \mathrm{HB})$ indicates better fabrics flexibility and elastic recovery.

To compare fabrics with the same structure but made of different material, the cotton fabric (i.e. sample $D$ ) has lower $B$ value than the DS polyester fabric (i.e. sample A), suggesting better flexibility and elastic recovery.
Lower $2 \mathrm{HB}$ indicates better recovery after bending deformation. Samples B-1, B-2, B-3 and B-4 have similar bending recovery as sample $D$ (cotton sample). Samples $A$ and $C$ were difficult to recover after bending at weft direction than other samples.

Samples B-1, B-2, B-3 and B-4 have similar $2 \mathrm{HB}_{\text {warp }}$ and $2 \mathrm{HB}_{\text {weft }}$ It indicates that locknit structure has balanced construction in two directions when using this DS polyester yarn with differential shrinkage component. For tricot and satin structure, its $2 \mathrm{HB}_{\text {weft }}$ is higher than $2 \mathrm{HB}_{\text {warp }}$.

For all fabrics, $B_{\text {warp }}$ is larger than $B_{\text {weft' }}$ implying that the weft direction has better bend flexibility. It is because the warp density is much higher than the weft density. Moreover, the length of underlap also influences the bending property in weft direction. When the underlap is shorter, the weft direction is easier to bend. Sample A has the shortest underlap resulting in the lowest $B_{\text {weft }}$ whilst sample $C$ has the longest underlap resulting in the highest $B_{\text {weft }}$.

\section{Surface property}

The result of the surface properties includes the coefficient of friction and geometrical roughness. Cotton fabric (sample D) has lower coefficient of friction $\left(F_{\text {warp }}=2.74 ; F_{\text {warp }} 2.15\right)$ in both directions against DS polyester fabrics, reflecting cotton fabric is more smooth in the inner surface. This might be the surface of DS polyester has high friction or the curls of filament due to shrinkage will create high friction. On the other hand, cotton fabric has higher geometrical roughness values $\left(R_{\text {warp }}=8.52 ; R_{\text {weft }}=7.07\right)$ than all DS polyester fabric when testing fabric inner surface. This is because the DS polyester has finer filaments and the shrinkage of fabric results in more dense texture.

The sample $C$ had highest roughness in warp $\left(R_{\text {warp }}=6.01\right)$, the lowest value is sample $A\left(R_{\text {warp }}=1.72\right)$. It suggests the roughness in warp direction of inner surface is associated with the knitting structure. Sample $C$ (in satin structure) had longest underlap, while sample A ( in tricot structure) $d$ has shortest underlap. But there is no such trend in terms of friction. For locknit structure in four densities, ]there is no significant difference between samples B-1, B-2, B-3 and B-4 in terms of friction and roughness. 


\section{Compression}

The result of compression properties includes compression energy (WC) which is measured at $50 \mathrm{cN} / \mathrm{cm}^{2}$ pressure and compression resilience (RC). WC indicates fabric bulkiness with higher value denotes bulkier feature. Table 4 suggests that cotton (i.e. sample D) is bulkier than most DS polyester fabrics except sample B-3.

$\mathrm{RC}$ indicates the ability of fabric to recover under compression deformation. Larger RC gives better recoverability of fabric after compression deformation. The DS polyester fabric had better recovery ability than the cotton one with its $\mathrm{RC}$ ranges from 51.660 to 62.290 . For locknit fabrics (samples B-1, B-2, B-3 and B-4), its RC decreases with fabric stitch density. In addition, for those DS polyester fabrics, it is observed that RC decreases with the increase of the length of underlap.

\section{Subjective evaluation of fabric handle}

\section{Cool- warm feeling}

Figure 2 demonstrates the subjective results of cool-warm rating under dry and wet conditions. In dry condition, sample 3 (cotton woven) was felt to be the warmest one among all woven fabrics whilst sample 7 (cotton weft knitted) provided warmer feeling than the corresponding weft knitted fabric made by polyester. It means that in dry condition $\left(25^{\circ} \mathrm{C}\right.$ and $65 \%$ R.H.), the subjects feel warmer when manipulating the cotton woven and cotton weft knitted fabrics than the corresponding polyester fabrics. This might be that the thermal comfort in steady state was mainly influenced by the moisture regain which positively related to the first thermal contact feeling [9].

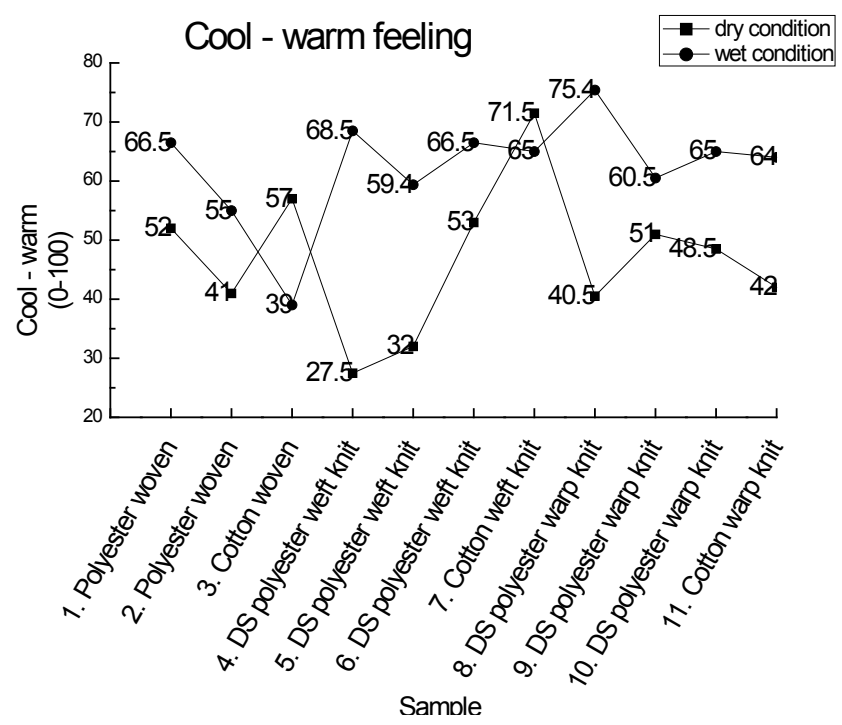

Figure 2. Subjective results of cool-warm rating under dry and wet conditions

Table 4. KES test results in terms of tensile, shearing, bending, compression, and surface property

\begin{tabular}{|c|c|c|c|c|c|c|c|c|c|}
\hline Test & Unit & $\begin{array}{c}\text { Test } \\
\text { direction }\end{array}$ & A & B-1 & B-2 & B-3 & B-4 & C & D \\
\hline \multirow{4}{*}{ Tensile } & \multirow{2}{*}{$\begin{array}{c}\mathrm{WT} \\
\left(\mathrm{N} \cdot \mathrm{cm} / \mathrm{cm}^{2}\right)\end{array}$} & Warp & 21.35 & 17.45 & 17.3 & 17.4 & 17.45 & 16.7 & 51.8 \\
\hline & & Weft & 39.95 & 38.9 & 22.3 & 20.25 & 16.35 & 16.5 & 49.4 \\
\hline & \multirow{2}{*}{$\begin{array}{l}\text { RT } \\
(\%)\end{array}$} & Warp & 56.44 & 53.58 & 54.34 & 55.62 & 57.02 & 56.29 & 24.81 \\
\hline & & Weft & 43.18 & 40.49 & 47.53 & 50.00 & 54.43 & 51.52 & 29.25 \\
\hline \multirow{4}{*}{ Shearing } & \multirow{2}{*}{$\begin{array}{c}\mathrm{G} \\
(\mathrm{N} / \mathrm{cm})\end{array}$} & Warp & 3.32 & 2.8 & 3.07 & 3.22 & 3.44 & 2.57 & 1.61 \\
\hline & & Weft & 3.77 & 2.63 & 2.94 & 2.99 & 3.09 & 2.59 & 1.49 \\
\hline & \multirow{2}{*}{$\begin{array}{c}2 \mathrm{HG} \\
(\mathrm{N} / \mathrm{cm})\end{array}$} & Warp & 5.48 & 4.7 & 5.85 & 5.7 & 5.95 & 4.78 & 5.8 \\
\hline & & Weft & 6.58 & 6.5 & 7.13 & 6.5 & 6.68 & 5.7 & 5.8 \\
\hline \multirow{4}{*}{ Bending } & \multirow{2}{*}{$\begin{array}{c}\mathrm{B} \\
\left(\mathrm{N} \cdot \mathrm{cm}^{2} / \mathrm{cm}\right)\end{array}$} & Warp & 0.0164 & 0.0227 & 0.012 & 0.0121 & 0.0122 & 0.0134 & 0.0066 \\
\hline & & Weft & 0.0024 & 0.008 & 0.0067 & 0.0077 & 0.0087 & 0.0144 & 0.0081 \\
\hline & \multirow{2}{*}{$\begin{array}{c}2 \mathrm{HB} \\
\left(\mathrm{N} \cdot \mathrm{cm}^{2} / \mathrm{cm}\right)\end{array}$} & Warp & 0.0068 & 0.0092 & 0.0068 & 0.0076 & 0.0086 & 0.0081 & 0.0099 \\
\hline & & Weft & 0.0154 & 0.0086 & 0.007 & 0.008 & 0.0079 & 0.0114 & 0.0088 \\
\hline \multirow{4}{*}{ Surface } & \multirow{2}{*}{ Friction } & Warp & 3.18 & 4.1 & 3.68 & 3.24 & 3.31 & 3.94 & 2.74 \\
\hline & & Weft & 3.54 & 3.05 & 3.39 & 3.06 & 3.85 & 3.62 & 2.15 \\
\hline & \multirow{2}{*}{ Roughness } & Warp & 1.72 & 3.07 & 2.22 & 5.44 & 3.83 & 6.01 & 8.52 \\
\hline & & Weft & 1.52 & 1.61 & 2.11 & 1.82 & 3.09 & 1.45 & 7.07 \\
\hline \multirow{2}{*}{ Compression } & \multicolumn{2}{|c|}{$\mathrm{WC}\left(\mathrm{N} \cdot \mathrm{cm} / \mathrm{cm}^{2}\right)$} & 0.169 & 0.194 & 0.206 & 0.320 & 0.229 & 0.212 & 0.319 \\
\hline & \multicolumn{2}{|c|}{$\mathrm{RC}(\%)$} & 62.290 & 56.937 & 55.003 & 54.920 & 53.737 & 51.660 & 28.143 \\
\hline
\end{tabular}


In wet condition, the polyester fabrics can provide warmer feeling than the corresponding cotton fabrics (as compared within woven sample group, weft knitted sample group, and warp knitted sample group) and this could attribute to the nonhygroscopic property of the material. For most of the samples, the wet fabrics were felt to be warmer than the corresponding dry fabrics and this is likely due to the warm testing environment $\left(25^{\circ} \mathrm{C}\right)$.

DS polyester warp knitted fabrics (samples 8, 9 and 10) have similar cool-warm feeling against cotton warp knitted fabrics (sample 11) in dry condition but warmer feeling in wet condition. The cool-warm rating for sample 8 is the highest in wet condition. That might be related to fabric weight and thickness since the warp knitted fabric made of DS polyester has higher fabric weight and higher thickness.

\section{Prickle-unprickle feeling}

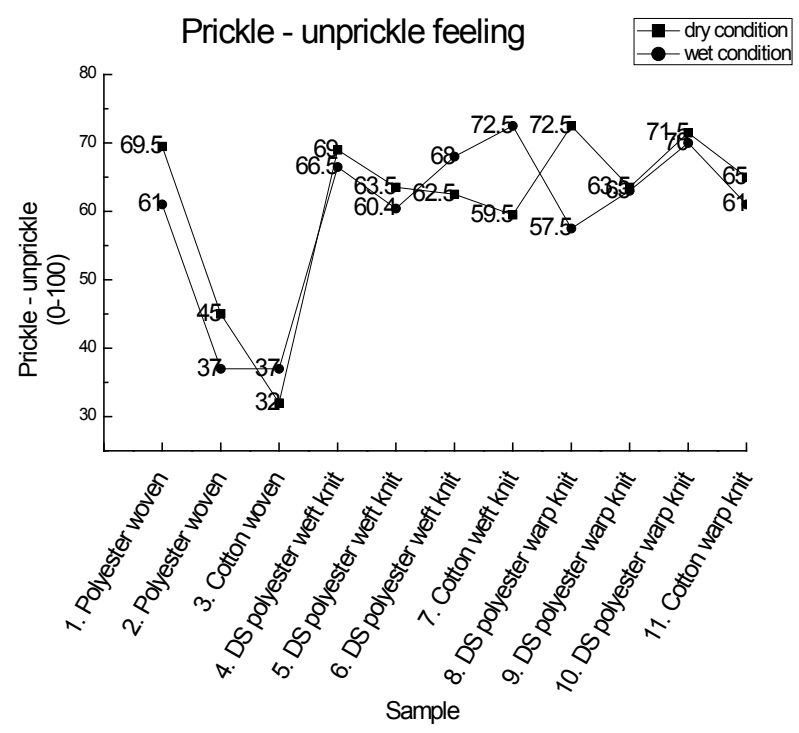

Figure 3. Subjective results of prickle-unprickle rating under dry and wet conditions

Figure 3 shows the subjective prickle-unprickle rating under dry and wet condition. Subjects felt more prickle for the fabric in wet condition than the corresponding dry fabric. The effect of attractive force in fabric-water and water-skin interface is more apparent for the wet fabric. Fabric tends to cling to skin for the wet fabric and so wet fabric is more prickle.

In dry condition, sample 8 made of DS polyester yarn is the least prickle one. In wet condition, the prickle feeling of samples 8,9 and 10 decreases with increase of length of underlap in the warp knitting structure. Sample 10 has longest underlap which gives less prickle among these 3 samples.

In both wet and dry conditions, samples 2 and 3 provide strongest prickle feeling due to the use of thick yarn and the hardness of the weaving structure.

\section{Rough- smooth feeling}

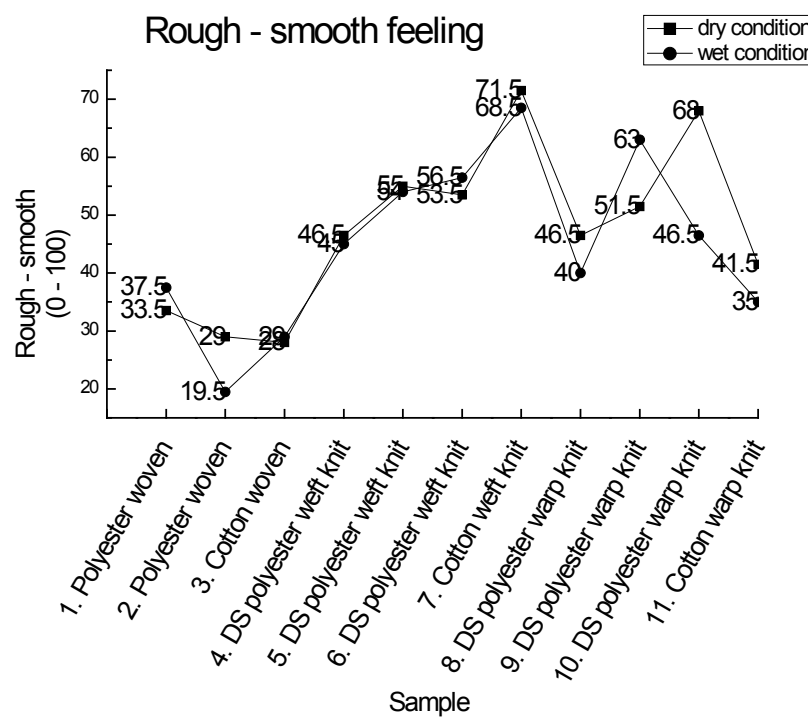

Figure 4. Subjective results of rough-smooth rating under dry and wet conditions

As shown in Figure 4, woven samples are rougher than the weft knit and warp knit samples due to hard yarn or weaving construction. The cotton weft knitted sample (i.e. sample 7) gives the smoothest feeling $\left(\right.$ rating $_{\mathrm{dry}}=71.5$ and rating $_{\text {wet }}=68.5$ respectively).

In dry condition, the smooth feeling of samples 8,9 and 10 increases gradually as the length of underlap in the warp knitting structure increase. Sample 10 has the longest underlap which makes fabric smoother among these three samples.

Generally, for the warp knitted sample group (samples 8, 9, 10 and 11), the fabrics made of DS polyester yarn has smoother surface than the cotton warp knitted fabric. This might be that the DS polyester warp knitted fabrics have higher density due to shrinkage. This result is coordinate with the KES surface property in objective evaluation. The sample 11 has the highest roughness among those four fabrics (see table 4 ).

\section{Discomfort- comfort feeling}

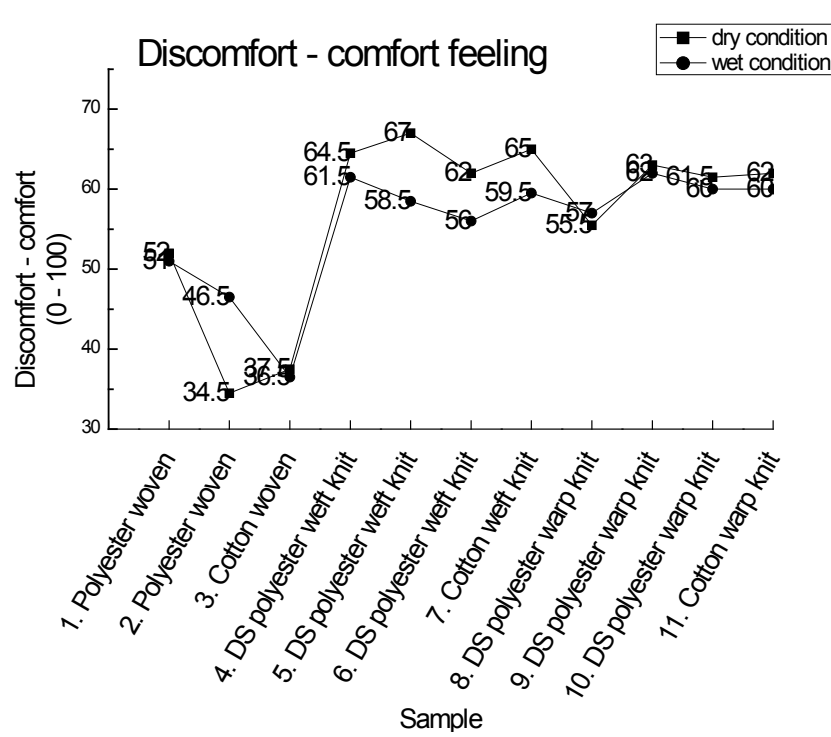

Figure 5. Subjective results of discomfort-comfort rating under dry and wet conditions 
Figure 5 shows that the woven fabrics have the lowest comfort rating. In general, fabrics which were tested under dry condition can provide more comfort feeling to subjects. The warp knitted fabrics (Nos. 8, 9 and 10) made by DS polyester yarns have similar comfort rating as the cotton warp knitted fabric (No.11). After wetting, sample 9 has the highest rating. This demonstrates the DS polyester warp knitted fabrics do not create any discomfort feeling when directly contacting to skin surface.

In dry condition, the weft knitted fabrics provide the greatest comfort among all the fabrics investigated. This might be contributed by the inherent texture feature of the weft knitted structure. However, for those wetted samples, the degree of comfort of the weft knitted fabrics is of similar level as the warp knitted fabrics.

\section{Polyester-like - cotton-like feeling}

The fabrics in dry condition has much higher value than the wet condition regarding polyester-like - cotton-like feeling (see Figure 6), implying that the wet fabrics is more cotton-like. The greatest rating at 72.5 was found in cotton warp knitted fabric (i.e. sample 11) in dry condition whereas it went down to much lower value at 26.5 in wet condition. In wet condition, warp knitted fabrics made of DS polyester yarn (i.e. samples 8, 9, 10) is more cotton-like than the corresponding cotton warp knitted fabric (i.e. sample 11). It demonstrated that the DS polyester warp knitted fabrics could provide a fluffy feel and perform as good as the real cotton fabric.

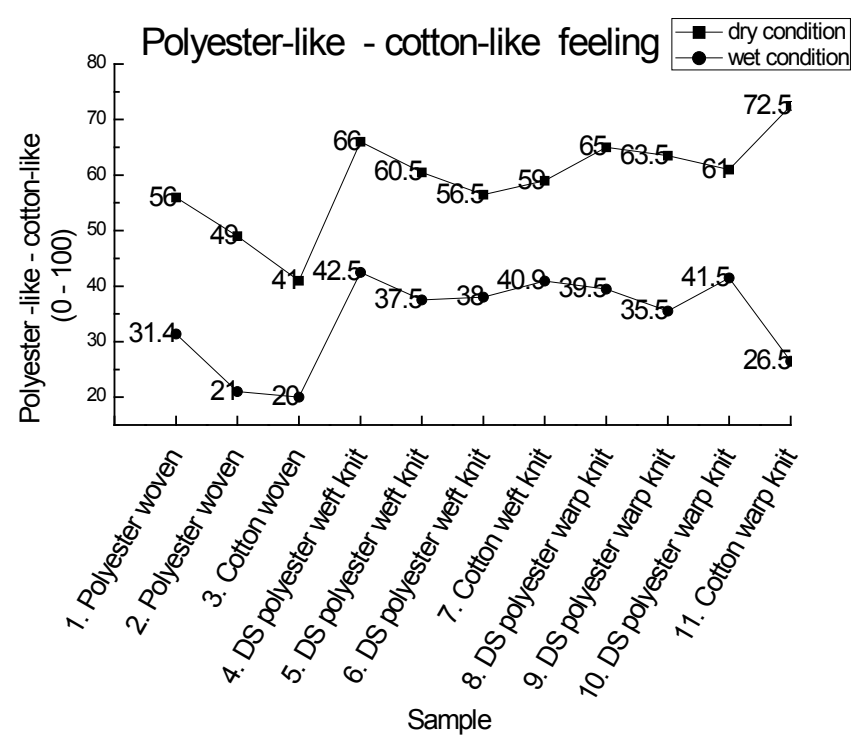

Figure 6. Subjective results of polyester-like-cotton-like rating under dry and wet conditions

\section{Clammy-dry feeling}

For the wetted fabrics, the clammy-dry feeling was evaluated and the result is shown in Figure 7 . The polyester woven fabrics (samples 1 and 2) was felt to be the clammiest one which is lower than corresponding cotton woven fabric (sample 3). However, this trend does not apply to weft knit and warp knit fabrics. For the weft knit fabrics, DS polyester fabrics (samples 4, 5 and 6) had higher rating than the corresponding cotton fabric (sample 7). Similar finding was obtained for the warp knitted samples. DS warp knitted fabrics (samples 8, 9 and 10) had higher rating than the corresponding cotton warp knitted fabrics (sample 11). Polyester filament has higher hydrophobicity and water cannot penetrate into intra fibre space easily. Instead, water may stay on the surface of the fabric and so giving clammy feeling. In general, the DS polyester warp knitted fabrics had similar clammy-dry feeling when compared to cotton warp knitted fabrics.

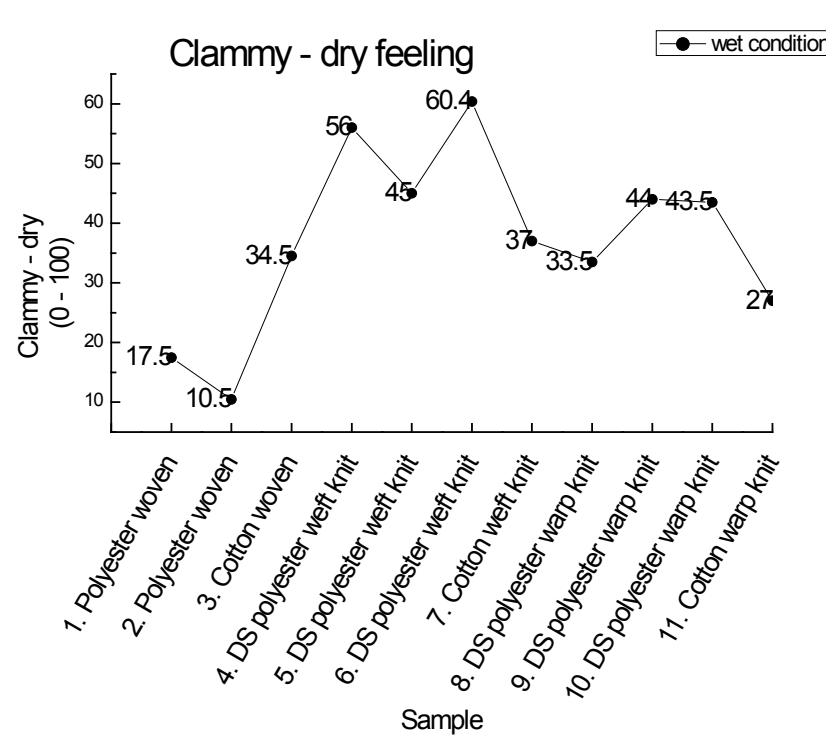

Figure 7. Subjective results of clammy-dry rating under wet condition

\section{Conclusions}

This study demonstrates that warp knitted fabrics made of DS polyester had better abrasion resistance than the cotton warp knitted fabric and this could attribute to higher strength of polyester yarn. However, the anti-electrical, pilling resistance of DS polyester warp knitted fabric is worse than the corresponding cotton warp knitted fabric and these could attribute to high breakage tension and low moisture regain of polyester filament. In addition, when compared with the cotton warp knitted fabric, lower water vapour permeability and air permeability were observed for the DS polyester warp knitted fabrics and these might be due to higher fabric weight and higher density resulted by higher yarn shrinkage. The deficiency of DS polyester warp knitted fabric can be improved by reducing the knitting density so as to improve its bulkiness and softness. Furthermore, DS polyester warp knitted fabrics provide better recovery under low stress mechanical pressure in terms of bending, compression, tensile, shearing and smoother inner surface as measured by KES-F.

The subjective evaluation result shows that the warp knitted fabrics made of differential shrinkage (DS) polyester had similar handle against cotton warp knitted fabric in terms of prickle, smooth, comfort and dry feeling in dry and wet conditions. The warp knitted fabrics had higher values in cotton-like rating in wet condition whereas it had lower values in dry condition 
against its control cotton warp knitted fabric. Apart from material, the effect of fabric structure was also studied and the woven, weft knitted and warp knitted fabrics were compared. In dry condition, the woven fabrics are more prickle, rough, uncomfortable compared with other samples in this study. In wet condition, the woven fabrics provide more clammy feeling than other samples in this study. Warp knitted fabrics give intermediate performance as compared with woven and weft knitted fabric in terms of fabric handle. Among these three structures, the weft knitted fabrics gave relatively comfortable and dry feeling.

\section{Acknowledgements}

This work was supported by the National Science Foundation of China under Grand 51403080 and 11302085; , Natrual Science Foundation of Jiangsu Province of China under Grand BK20140161 and BK20151129.; Fundamental Research Funds for the Central Universities of China under JUSRP11448; the Innovation fund project of Cooperation among Industries, Universities \& Research Institutes of Jiangsu Province of China under No. BY2014023-34 and BY2014023-20.

\section{References}

[1] Ozturk, M. K., Nergis, B. , Candan, C. (2011) A study of wicking properties of cotton-acrylic yarns and knitted fabrics. Textile Research Journal, 81(3), 324-328.

[2] Afzal, A.,Hussain, T., Malik, M. H., Rasheed, A., Ahmad, S., Basit A., Nazir, A. (2014) Investigation and modeling of air permeability of Cotton/Polyester blended double layer interlock knitted fabrics. Fibers and Polymers, 15(7) ,1539-1547.

[3] Moghassem, A. R.,Fakhrali, A.(2013) Comparative study on the effect of blend ratio on tensile properties of ring and rotor cotton-polyester blended yarns using concept of the hybrid effect. Fibers and Polymers 14(1), 157-163.

[4] Naebe, M., McGregor, B. A. (2013) Comfort properties of superfine wool and wool/cashmere blend yarns and fabrics. Journal of the Textile Institute, 104(6),634-640.

[5] Prakash, C.,Ramakrishnan, G., Koushik, C.V.(2013) Effect of blend proportion on moisture management characteristics of bamboo/cotton knitted fabrics. Journal of the Textile Institute, 104(12),1320-1326.

[6] Su, C.L.,Fang, J.X. (2006) Optimum Drafting Conditions of Non-circular Polyester and Cotton Blend Yarns. Textile Research Journal, 76( 6),441-447.

[7] Su, C.L., Fang, J.X.,Chen, X.H., Wu ,W.Y. (2007) Moisture Absorption and Release of Profited Polyester and Cotton Composite Knitted Fabrics. Textile Research Journal, 77(10), 764-769.

[8] Oguz,D., Derya.U. (2013) Thermal comfort properties of Viloft/cotton and Viloft/polyester blended knitted fabrics. Textile Research Journal, 83(16), 1740-1753.

[9] Bedek, G., Salaun, F., Martinkovska, Z., Devaux, E., Dupont. D. (2011) Evaluation of thermal and moisture management properties on knitted fabrics and comparison with a physiological model in warm conditions. Applied Ergonomics , 42(6), 792-800.

[10] Wardiningsih, W., Troynikov, O. (2012) Influence of cover factor on liquid moisture transport performance of bamboo knitted fabrics. Journal of the Textile Institute, 103(1), 89-98.

[11] Sampath, M.B., Aruputharaj, A., Senthilkumar, M., Nalankilli, G. (2012) Analysis of thermal comfort characteristics of moisture management finished knitted fabrics made from different yarns; Journal of Industrial Textiles, 42(1), 19-33.

[12] Troynikov, O., Wardiningsih, W. (2011) Moisture management properties of wool/ polyester and wool/ bamboo knitted fabrics for the sportswear base layer. Textile Research Journal, 81(6), 621-631.

[13] Shaikh, T. N., Bhattacharya, S. S. (2011) Deriving an empirical formula to determine the optimum level of falsetwist in mechanically-crimped textured polyester yarn. Textile Research Journal, 2011, 81(19), 1995-2005.

[14] Tavanai, H., Morshed, M., Moghaddam, A. (2013) Production of high bulk polyester filament yarn. Journal of the Textile Institute, 104 (1), 1-6.

[15] Shaikhzadeh Najar , S.,Seyed-Esfahani M. H., Hadi, H. (2005) The effect of blend ratios of unrelaxed and relaxed acrylic fibres on physical properties of high-bulk worsted yarns. The Journal of the Textile Institute, 96 (5), 311-318.

[16] Ciesielska-Wróbel I. L., Langenhove, L. V. (2012) The hand of textiles - definitions, achievements, perspectives - a review. Textile Research Journal, 82(14), 1457-1468.

[17] Shyr, T.W., Lai, S.S., Lin, J.Y.(2004) Approaches to Discriminate the Characteristic Generic Hand of Fabrics. Textile Research Journal, Vol.74(4), 354-358.

[18] Varshney, R. K., Kothari, V. K., Dhamija, S. (2011) Influence of polyester fibre fineness and cross-sectional shape on low-stress characteristics of fabrics. Journal of the Textile Institute, Vol.102(1),31-40.

[19] Khoddami, A., Carr, C. M., Gong, R. H.(2009) Effect of Hollow Polyester Fibres on Mechanical Properties of Knitted Wool/Polyester Fabrics, Fibers and Polymers, Vol.10(4),452-460.

[20] Das, A., Kothari, V. K., Balaji, M. (2007) Studies on cottonacrylic bulked yarns and fabrics. Part I: Yarn characteristics. Journal of the Textile Institute, Vol.98 (3), 261-267.

[21] Grabowska K. E., Ciesielska-Wróbel I. (2014) Basic Comparison of the Properties of the Loop and Frotte Yarns, Woven and Knitted Fabrics. Autex Research Journal, Vol.14(3), 135-144.

[22] Ishtiaque, S.M., Das, A.,Kundu, A.K.(2014) Ring frame process parameters and fabric comfort. Part I-low-stress mechanical properties of fabrics. Journal of the Textile Institute Vol.105 (3), 348-355.

[23] Kim, H. A., Kim, S. J. (2013) Mechanical properties of worsted fabrics for emotional garment to the rapier loom characteristics. Fibers and Polymers, Vol.14(12), 2163-2168.

[24] Tang, K. P., Fan, J. T., Zhang, J. F., Sarkar, M. K., Kan, C. $W$. (2013) Effect of Softeners and Crosslinking Conditions on the Performance of Easy-care Cotton Fabrics with Different Weave Constructions. Fibers and Polymers, Vol.14(5), 822-831.

[25] Lam, Y. L., Kan, C. W., Yuen, C. W. M.(2014) Objective measurement of hand properties of plasma pre-treated cotton fabrics subjected to flame-retardant finishing catalyzed by zinc oxide. Fibers and Polymers, Vol.15(9), 1880-1886.

[26] Mori, M., Fujimoto, T., Murakami, M., Matsudaira, M. (2013) Correlation with itchy feeling of fabric handling change by 
physicochemical processing of woolen fabric. Fibers and Polymers , Vol.14(12), 2202-2211.

[27] AATCC Committee RA63, Water Resistance, Absorbency and Wetting Agent Evaluation Test Methods: Vertical Wicking of Fabrics.

[28] ASTM D4970/D4970M-2010-Standard Test Method for Pilling Resistance and Other Related Surface Changes of Textile Fabrics: Martindale Tester.

[29]ASTM D3884-2009-Standard Guide for Abrasion Resistance of Textile Fabrics (Rotary Platform, DoubleHead Method).

[30] China GB/T5453-1997-Textiles-Determination of the permeability of fabrics to air.
[31] China GB/T 12704.1-2009-Test method for water-vapour transmission of fabrics-Part 1:Desiccant method.

[32] Oner, E., Atasagun, H.G., Okur, A., Beden, A.R., Durur, G. (2013) Evaluation of moisture management properties on knitted fabrics. Journal of the Textile Institute, 104(7), 699-707.

[33] Gun, A. D. (2011) Dimensional, physical and thermal comfort properties of plain knitted fabrics made from modal viscose yarns having microfibers and conventional fibers. Fibers and Polymers, 12(2), 258-267.

[34] Khoddami, A., Carr, C. M., Gong, R. H. (2009) Effect of hollow polyester fibres on mechanical properties of knitted wool/polyester fabrics; Fibers and Polymers, 10(4), 452460. 